\title{
Time for Realignment: The HR Ecosystem
}

\author{
Scott Snell \\ University of Virginia, snells@darden.virginia.edu \\ Shad Morris \\ Brigham Young University, morris@byu.edu
}

Follow this and additional works at: https://scholarsarchive.byu.edu/facpub

Part of the Human Resources Management Commons

\section{Original Publication Citation}

Snell, S. \& Morris, S. Time for Realignment: How Complex Adaptive Systems Can Help Reframe SHRM Research. Forthcoming. Academy of Management Perspectives.

\section{BYU ScholarsArchive Citation}

Snell, Scott and Morris, Shad, "Time for Realignment: The HR Ecosystem" (2020). Faculty Publications. 3677.

https://scholarsarchive.byu.edu/facpub/3677

This Peer-Reviewed Article is brought to you for free and open access by BYU ScholarsArchive. It has been accepted for inclusion in Faculty Publications by an authorized administrator of BYU ScholarsArchive. For more information, please contact ellen_amatangelo@byu.edu. 


\title{
TIME FOR REALIGNMENT: THE HR ECOSYSTEM
}

\author{
Scott A. Snell \\ University of Virginia \\ SnellS@darden.virginia.edu \\ Shad S. Morris \\ Brigham Young University \\ morris@byu.edu
}

\begin{abstract}
The concepts of fit and alignment have been foundational to the field of strategic human resource management. And while the theoretical premises that underlie these concepts remain useful and intuitively compelling, the lack of empirical evidence to support them proves problematic. Part of the reason, we suspect, is that our research on fit and alignment does not fully reflect realities of contemporary organizations or the practical challenges faced by managers. We argue that HR researchers have an opportunity to reframe concepts of fit and alignment to better reflect the complexities and dynamics of contemporary models of strategy and organization. We suggest that an ecosystem perspective can help us study the processes of alignment, not just its static features. It can help to depict the interactions among elements of the workforce compositions, capabilities and cultures. Because these interactions are myriad and constantly in flux, HR researchers might approach alignment in an evolutionary way where practices are constantly changing and then being reintegrated into the system to assure consistency and synergy. The benefit of doing so might reinvigorate research on strategy and $\mathrm{HR}$.
\end{abstract}

Keywords: complexity theory, human capital theory, strategic HRM, human resource management 
For many years, working in upstate New York where the winters are unyielding, we sometimes got stuck while driving in deep snow. In such cases, rather than just spinning our wheels, we found it useful to back up a little in order to coax a fresh start moving forward. We think a similar approach may be helpful to the field of strategic human resource management (SHRM). By our own admission, the field is stuck a little, not making as much forward progress as we might like. And that's frustrating because companies depend more on the talents, energies, and imagination of people than ever before. The purpose of this paper is to back up, get a fresh perspective, and offer some ideas about building new momentum.

The concepts of fit and alignment have been foundational to the field of strategic human resource management almost since its inception (cf., Baird and Meshoulanm, 1987; Schuler and Jackson, 1987). And while the theoretical notion that HR practices need to reinforce one another (i.e., internal fit) and serve the broader organization strategy (i.e., external fit) remains intuitively compelling, the lack of empirical evidence and advancement of practice proves problematic. Part of the problem, we suspect, is that research on fit and alignment does not fully reflect the realities of today's organizations or the practical challenges faced by managers. In this paper, we argue that SHRM researchers have an opportunity to reframe concepts of fit and alignment to better reflect the complexities - and dynamics - of contemporary models of strategy and organization. In particular, we advance the idea that we can better understand fit and alignment within the context of an HR ecosystem with many related elements interacting with one another and co-evolving with the organization. The benefit of doing so might be to reinvigorate research on SHRM.

In the following pages, we go back to the origins of research on HR fit and alignment to get a running start. We review the organizational challenges the concepts were designed to address, and the ways in which it changed the way we conceived strategic HRM. Following this, we examine the realities of today's organizations, particularly with regard to strategic complexity and change. We point out the need for fit research to better incorporate concepts of workforce complexity and change to more 
effectively depict the scope of how organizations actually function. We then introduce the HR Ecosystem as a framework to help our field take a fresh perspective on the complex and adaptive nature of alignment and how to achieve it over time. This new perspective helps us understand that HR fit and alignment is not just about consistency of HR practices with one another or a strategy, but rather about nurturing the richness of variation required for strategy, while simultaneously improving convergence of those elements with one another. This is a more complex and dynamic view of fit and alignment than we have traditionally taken. We will discuss how the HR ecosystem includes processes of both divergence and convergence within the composition of the workforce, its capabilities, work relationships and subcultures. To help illustrate our perspectives, we draw upon real-world situations to offer evidence for how these processes of convergence and divergence are taking shape. We conclude by offering recommendations on how we might study strategic alignment going forward.

\section{ORIGINS OF RESEARCH ON ALIGNMENT}

Context is important. During the 1980s, as companies faced the challenges of global competition, diversification, total quality management, outsourcing, strategic partnerships, and the like, a new "systems" logic began pervading organizations. Its affect was to recast the field of strategy as well as the broader agenda of HRM. Observers such as Mason and Mitroff (1981: 15) noted that we needed to deal with organizational problems "in a holistic or synthetic way as well as in an analytic way." The complexity of organizations invited us to elevate our thinking to a higher level of abstraction. So in addition to analyzing the individual elements of the HR function, we began to also conceive of ways in which the pieces fit together into a more powerfully integrated system for managing people. It was at this time that the concept of HR strategy first appeared in the literature (Walker, 1980; Tichy, Fomburn, and DeVanna, 1982).

We began to think of HR strategy as a "pattern of planned HR deployments and activities" (Wright and McMahan, 1992: 298) in order to capture ideas of convergence among various decisions, as well as continuity over time. We began a search for concepts that best describe the nature of that 
"pattern" to effectively highlight the most important aspects of strategy. Baird and Meshoulam (1988) wrote a landmark piece on the principles and parameters that should govern HR strategy and proposed that two issues - internal and external fit - were paramount. It changed the field by creating a stream of research that focused on a more macro perspective where organizational performance became an important dependent variable, rather than focusing on individual practices and how they influenced employee behaviors.

Why were the concepts of fit so influential? Why did they matter? According to Baird and Meshoulam, a focus on fit was a response to increasing organizational complexity. When organizations are small, or at start-up, owners and managers can deal with people issues on their own, informally, and the whole notion of HR may be implicit in their approach to leadership. But as the organization grows, and administrative decisions become more complicated, HR-related policies and practices diverge. The organization can fragment and drift. The point of looking at fit was to help managers keep the organization together - integrated and on track - as the challenges of the firm became more complex. It gave us two important ways to calibrate HR effectiveness.

\section{Internal Alignment}

Internal (horizontal) fit aims at establishing congruence, consistency and coherence among sets of practices so that they are unified and mutually reinforcing. Internal fit casts HR as a package deal, where the most important concerns are whether the sets of practices are complementary, compensatory, or synergistic (Chadwick, 2010). When done well, internal fit eliminates noise in the system, preventing “deadly combinations" where HR practices are inconsistent and send conflicting signals (Boxall and Purcell, 2000). Beer et al (1984) were the first to propose a systems-based approach to HR strategy that exemplified the notion of internal fit. But soon others began to show the evidence of internal fit (Arthur, 1994; Huselid, 1995; MacDuffie, 1995; Snell, 1992). We ascribed a number of concepts, most notably "high performance work systems" (Huselid, 1995), to describe not only what these systems were, but also what their impact on the organization might be. 


\section{External Alignment}

External (vertical) fit aims to ensure that the HR system is appropriate for the particular needs of the business. It conveys the idea that the key imperatives for HR vary from one context to the next. The job of managers is to align the overall HR system for its environment. It stops short of fully specifying a contingency view that matches different HR systems to different strategies, but it does convey the notion that while there may be more than one "good" approach, not all approaches are equally good. And some, frankly, won't work. Miles and Snow (1984) were notably among the first to develop a typology of competitive strategies that extended to include associated HR strategies. Soon others followed (Schuler and Jackson, 1987; Olian and Rynes, 1984).

These two ideas of fit are powerfully simple, and have become de facto criteria for evaluating HR strategy (Delery \& Roumbi, 2017). What have we done with them? Have we used the concepts and frameworks to guide our research and help organizations manage their strategic challenges? Well, yes and no. The concept of fit helped us to establish a platform for discussion and debate about ideas such as contingency, synergy, and best practice in HR. They became the means by which we began to understand and communicate the logic of business strategy that was, until that time, largely foreign to many of us. Perhaps most importantly, the concepts of fit and alignment helped open the aperture to organizations and gave us a way to scrutinize what was potentially most important for successful strategy execution.

Progress, we believe, requires that we update and reframe our notions of alignment by examining some of the primary assumptions within the SHRM field and present a model that more appropriately allows us to examine the realities of internal and external alignment. Let's go back to our original questions about research and practice. First, if the concept of internal fit is to help managers ensure unity and internal consistency with regard to how they manage people, what is it that may be coming apart and therefore what needs to be (re)aligned? Do we always want uniformity in our HR systems or should we allow for variation and complexity? The reality is that high performing organizations routinely design 
HR systems that have some built-in inconsistencies, and include HR practices that are noncomplementary, divergent, even competing. Is that a mistake?

Second, if external fit helps managers align the unique aspects of people to the broader needs and functions of the business, how are those needs different today than in the past and what needs to be aligned? Do we always want consistency and continuity in the way we manage people or should we allow for adaptation and change? Does HR have a role to play when the goal is to shake things up? These questions help us to examine the role of the HR system as it relates to an environment where strategies, cultures, capabilities and workforce compositions inside a single organization are complex and constantly changing.

\section{THE QUESTION OF COMPLEXITY}

Let's start with the question of complexity. Our premise of course is that organizations and their environments are complex systems made up of many different parts that have many interactions. As we noted, the concept of fit originated from our efforts to manage organizational complexity more effectively. How has the question of complexity informed our research in SHRM, and particularly with regard to fit?

We can address the question on at least two levels. How is the concept of complexity inherent in strategy? And how is complexity inherent in the workforce? The answer to these questions informs the way we might reframe HR systems themselves, particularly by expanding our concepts of fit and alignment.

\section{Strategic Complexity—One Strategy or Many?}

In many ways, strategy addresses the question of how firms manage complexity. Organizations don't just react to environmental complexity, they enact it. Decisions about markets, coalitions, technologies, size, structure, etc. all come down to strategic choices about the complexity of the firm's “organizational domain.” 
And those choices have ramifications on the requirements of organizational design and decision making. For example, increased diversification leads to a shift from simple functional structures to multifaceted divisions. The "law of requisite variety" (Ashby, 1962) suggests that every system needs to reflect the complexity of its environment or it won't be able to respond to the diversity of problems and opportunities it faces. Increasing external complexity requires increasing internal complexity. A closely related concept is the notion of entropy - all systems are predisposed toward disarray and randomness, dissipating energy along the way. It takes far more energy to keep a system together, aligned and organized, than to have it disperse.

So there's the challenge of fit in strategy: How to hold the system together as it expands, ensuring positive engagement and unity. Like any system, an organization must generate more productive energy than it expends, or it will literally "dis-integrate" and won't survive. Diversified companies like GE, Tata (India), or even Google, are examples of companies that face the reflective challenges of complexity and entropy. Their success in creating a unified portfolio of complex businesses comes down to the management of people and culture(s) so central to HR agenda.

The issue we run into with much of our prior SHRM research is that it doesn't always capture the complexity or dimensionality of strategic choice. Early SHRM research, for example, conceptualized strategy as categorical (e.g., defenders/ prospectors, low cost/differentiation) or unidimensional (e.g., product-market variation), but the reality of organizations is far more complicated. Organizations often pursue strategies that incorporate multiple business units, multidimensional value propositions, multiple capabilities, and complex value chains/networks. How have we addressed that in our research?

Given the importance of fit and alignment in the context of strategic complexity, it's somewhat surprising that there is less HR research on this than one might expect. Rowe and Wright (1997) studied the relationship between diversification strategies and HRM controls. They found that firms pursuing strategies of related diversification had more focus on achieving fit and used a combination of behavior, outcome, and clan controls. In contrast, firms pursuing a strategy of unrelated diversification accorded 
more flexibility, exhibiting a relative emphasis of the use of outcome controls. More recently, Morris and colleagues (2015) found that within the same firm, different units and even project teams will draw upon different control mechanisms to achieve different strategic objectives. Specifically, project teams will use outcome controls to increase innovation and process controls to increase efficiency. So there is some evidence that complexity begets complexity in SHRM.

Nevertheless, is there also evidence that HR fit and alignment helps hold complex organizations together? Given the substantial increase in M\&A activity over the last two decades, it's surprising that we haven't seen more research on how HR practices enable strategic integration. HR has a significant role to play in post-merger integration in order to create synergies. We know anecdotally that, when mergers fail, it is most frequently attributed to cultural and HR-related issues of fit. But there is a dearth of empirical evidence. Birkinshaw, Bresman and Hakanson (2002) found that initial HR-related integration enables post-merger task integration to go more smoothly. The result is that both parties in the deal develop greater interdependencies.

In a similar vein, given the increase of joint ventures, strategic alliances, and inter-organizational networks, we have many opportunities to expand our notions of fit and alignment in strategic HR. The causes of failure in these situations are most often associated with the management of people. For example, Royal Dutch Shell pointed out that many of its operations in Africa and the Middle East were joint ventures or strategic alliances. In talking with the HR managers of these operations, they pointed out that completely aligning HR practices across the organization was neither possible nor advisable when your alliance partners were local governments with different employment goals and laws (Morris \& Snell, 2011). Nevertheless, there is very little research on how HR systems can align these differences and hold these alliances together (Schuler, Tarique, \& Jackson, 2004).

These strategic challenges reinforce an important point regarding HR fit and alignment: To execute increasingly complex strategies, senior executives need HR to help support variation and 
difference in the organization, and to continually recombine and integrate that variation as well (Morris, Snell \& Bjorkman, 2016).

The challenges of complexity may be more subtle and nuanced than in cases of multiple business units, corporate diversification, M\&A, joint ventures, and the like. Complexity can grow internally out of competing priorities and commitments. For example, stakeholder theory (Freeman, 1984) suggests that organizations are often the nexus of many different parties who have inconsistent and competing interests. Strategy in this context must balance and integrate the financial, political, environmental, and social interests of different stakeholders. HR alignment is both more difficult and more important in this context (Mitchell, Agle, \& Wood, 1997). Again, we don't see a lot of research examining alignment within these complex contexts (Guest \& Conway, 2011). And we are left wondering why?

Competing priorities are inevitable in complex organizations. Gone are the days when conventional wisdom held that firms pick a strategy, say low cost or differentiation, and avoid getting "stuck in the middle" (Hill, 1988). Top quartile companies across a range of industries offer multidimensional value propositions, and develop complex sets of capabilities to deliver on them. So how does HR help such organizations attend to different value propositions and simultaneously keep the organization integrated?

Let's step back for a moment. Each of these strategic challenges represents choices that require organizational complexity. The concept of HR alignment is important, but to address it appropriately, we need to modify our framing of the issues where we examine how organizations first allow for variation and divergence in their practices and systems and how they integrate them back together. These same choices apply to the nature of the workforce-its composition, capabilities, and culture(s).

\section{Workforce Complexity—One Workforce or Many?}

Strategic complexity highlights the potential role of HR to manage organizational variation or divergence. Unfortunately, in our efforts to view HR more strategically, we perhaps cast it too simplistically. We tend to aggregate - both conceptually and empirically - all employees into one 
comprehensive "workforce," studied as though it were managed as a single entity. For example, early work on high performance work systems included data for both exempt and non-exempt employees, and used a weighted average to represent the workforce as a whole. Delery (1998; p296) took issue with this approach, noting that it "assumes that all employee groups are equally important." We agree that it may be a mistake to gloss over potentially significant differences among various cohorts in complex organizations.

While aggregation offers parsimony, and helps isolate a particular phenomenon, it is an analytical compromise that treats variation within the firm as noise. Lepak and Snell (1999) offered an architectural perspective of HR to better capture the complexities of workforces within firms. The framework begins with an assumption that different employees contribute in different ways to organizations. The approach builds on work by Osterman (1987) and others who argued that different employment subsystems coexist in firms. Lepak, Takeuchi, and Snell (2003) found that higher performing firms utilize a broader array of employment modes and forms of human capital, each with their own distinctive characteristics. Rather than identifying one best HR system that fits with a given strategy, that research suggests that the complexity of the HR system needs to reflect the complexity of the workforce and the associated business demands.

Becker, Huselid, and Beatty (2009) built on these ideas and championed the merits of a differentiated workforce, and the importance of identifying strategic jobs ("A" positions) that are central to a firm's core capabilities. This approach offers great promise for capturing the complexities of the workforce and its connection to strategy.

Ployhart, Nyberg, Reilly and Maltarich (2013: 371) took the ideas even further, noting that, while a diverse workforce is important, competitive advantage depends on how these diverse types of human capital are combined and integrated. They noted that "multiple types of human capital resources may be combined within and across levels, via processes of emergence and complementarity..." and that "nearly 
all human capital resource combinations are complex, are firm-specific, and lack strategic (or efficient) factor markets."

How much do we know about HR's role of "fitting" different employee groups together? Should that be a key factor in our conception of fit and alignment? We believe it could. The form and nature of varied combinations may be as important as anything else may. In today's environment, collaboration is more prevalent than ever, in part because people need to work across organizational boundaries (Morris, Shenkar and Mackey, 2018). Some estimates suggest that over the past two decades the time spent by managers and employees in collaborative activities has ballooned by more than 50 percent (Cross, Rebele, and Grant, 2016). Why? Because in a knowledge-based economy, capability is distributed crossfunctionally and the organization's stock of knowledge transcends any one set of individuals or business units (Tsoukas, 1996).

Workforce complexity extends even beyond the firm. Organizations rely not only on their own talent; they also draw on those from other firms to generate economic value. Work tends to be carried out in cross-boundary contexts of inter-organizational networks, and the upshot is, as Swart and Kinnie (2014: 2) put it, "firms manage people they do not directly employ and employ people they do not manage." Does this represent the lack of alignment and fit, or merely a different form? The impact on HR is both important and largely unstudied to date. Swart and Kinnie (2014) noted that our traditional HR models are more suited to an industrial economy, which assumes a single employer and where work is carried out within a set of clearly defined boundaries. Nevertheless, as the lines blur, and boundaries become more amorphous, have our concepts of strategic fit and alignment kept up?

How do we conceive of HR alignment in a networked environment where there are structural tensions, relational challenges, and social influences? How do the HR systems help facilitate both the individual's work and the collaborative outcomes? As the nature of work changes in this context, so too will the nature of HR strategies. Organizations cannot easily control the exchanges and relationships among divergent sets of employees. Those who conceptualize organizations as networks and knowledge 
communities understand the difficulty of defining and managing across the boundaries of organizations. So in addition to traditional work, their effectiveness depends on managing the relational bases of organizations as well.

Our research on alignment inevitably needs to address how the complex set of values, attitudes, beliefs, and culture(s) among diverse groups of employees is perhaps more important to success than ever. Leanna and VanBuren (1999), for example, laid out a model of social capital that explains how HR practices can elevate the levels of trust and associability (willingness and ability to interact) among different people to encourage widespread cooperation and sharing of knowledge. Kang, Morris, and Snell (2007) elaborated on how firms can use HR systems to address the cognitive, structural, and affective elements that define these diverse relationships.

As the complexity of organizations and the nature of work expands, it is clear that we need to think about the broader ecosystem of people working in collaboration. Within that ecosystem, there is likely to be considerable variety, and that variety is a source of richness and value. But it needs to be connected as a vibrant system. We have an opportunity to evolve our thinking about how HR can create better integration and strategic functionality to facilitate performance in a complex setting.

In summary, these questions all invite a more complex view of fit and alignment within the HR ecosystem. Not only are organizations dealing with multiple strategies and stakeholders, they are also dealing with multiple workforces. Those workforces are comprised of multiple workgroups, multiple talent pools, multiple employment relationships and cultures. Addressing the complex ecosystem of workers requires a broader understanding of how fit and alignment simultaneously allow for divergence among different employment groups while at the same time enable a convergence in how they are managed. Just to be clear, these issues may all increase the importance of HR alignment, though perhaps not in the way we have traditionally studied it.

\section{A Complex Solution-Complex Alignment}


To address the question of complexity in our research, we need to expand our concept of HR alignment to address the multifaceted problems that organizations face. Let's not fall into the trap of simplifying strategy and HR, and miss the opportunity to see their challenges through a more sophisticated lens. The world is not that simple, and as one of our colleagues put it, "[some of our research] is designed to prove less than we already know."

We need to stop framing strategy in simple terms that are convenient to HR researchers, and start framing HR in terms that are useful to strategy researchers. We can begin with the premise that the HR system needs to reflect the complexity of strategic priorities and the multiplicity of work arrangements that supports it.

But let's not stop there. Complex alignment does not just identify differences; it also addresses the ways those differences are knitted together. Issues of compatibility, synergy and integration work hand in hand, setting a path for both divergence and convergence in the organization. Any organization has to balance these possibly conflicting demands with its aspirations of achieving between-HRM system fit while remaining flexible in the competitive landscape. Kepes and Delery proposed what they call the challenge of "between-HRM system fit" that is, the alignment of different HRM systems with the company's broader HRM architecture. Because there are "different types of HRM systems used to manage different types of employees within the firm, it is essential to discuss the degree to which these different HRM systems within an organization actually fit together to support the overall HRM strategy. This type of fit has been neglected in the SHRM literature" (2008: 391).

Acknowledging the complexity of the HR system architecture doesn't automatically imply that some HR initiatives might not cover all employees. In fact, it highlights the fact that the HR architecture comprises multiple sub-systems, and part of our efforts to understand the organization is to study how these subsystems interact with one another, and what their net effect is on organizational performance. In other words, we need to be more explicit about (a) how we manage differences and (b) how we reintegrate those differences through HR practices. For example, how do corporate HR policies and 
practices align with those in different business units and functions? In a global context, how do local systems cohere or diverge with those that are global? How might their joint effects create a more robust transnational talent portfolio rather than one that is merely multi-domestic (Morris and Snell, 2011)? What is common and what is unique, and why? How does complexity affect the need for difference, or the possibilities for compatibility or complementarity? How (well) do the HR philosophies, principles, policies, programs, processes, and practices align (Schuler, 1992)?

There are so many questions, and the reality is these are the alignment and fit challenges that organizations deal with on an ongoing basis. They should inform more of our research. We may be missing an important opportunity. To address the issue of complexity in alignment and fit in our research, our default often is to dig deeper into the granular elements of multiple HR practices in combination. For example, we still debate whether different HR practices, such as selection, training, performance management, etc. have additive or multiplicative (statistical) effects on performance (Delery, 1998). There is nothing wrong with that approach particularly, as it gives legitimacy to the importance of internal fit. But such an approach may miss the bigger picture.

We would suggest that researchers could spend less time looking down into the detailed statistical interactions of HR practices, and look up - and out - to the broader strategic context of organizations. In fact, Baird and Meshoulam's original work on internal and external fit wasn't about traditional HR practices at all. It wasn't about whether selection fit with training, it was about whether alignment of the HR function was keeping up with the demands of an increasingly complex organization (e.g., involvement in strategy, HR portfolio, use of technology, environmental scanning, etc.).

Given this, we argue that we need to work harder to describe and understand the nature of the broader human resource ecosystem. We would suggest that complexity exists in at least four subsystems within that larger ecosystem: (a) strategy, (b) composition, (c) capabilities, and (d) culture. As organizations increase in strategic complexity, our research on fit and alignment needs to show how the HR ecosystem reflects that complexity, helps to nurture it, and in what ways to hold it together. The goal 
of alignment in these instances is not to simply unify or homogenize the organization, but rather to harmonize complimentary assets in order to support the richness of difference while preserving the integrity of the whole. Table 1 describes the different complexities that exist within each of these subsystems. We would suggest that traditional HR practices (selection, job design, training, compensation, etc.) are tools used to manage both divergence and convergence within that ecosystem. However, they're not the only things worth studying; they may not even be the most important.

Proposition 1: In order to address the challenges of alignment in contemporary organizations, we need to frame HR as a more complex ecosystem. That HR ecosystem is comprised of many interacting parts that include differentiated human capital capabilities, segmented cultures, multiple workforce compositions, as well as strategic complexity.

Table 1: Alignment Complexity

\begin{tabular}{|c|c|c|}
\hline & DIVERGENCE & CONVERGENCE \\
\hline Strategy & $\begin{array}{l}\text { Globalization, diversification, strategic } \\
\text { alliances, M\&A, multi-dimensional } \\
\text { value propositions }\end{array}$ & $\begin{array}{l}\text { Post-merger integration, synergy, co- } \\
\text { specialized assets. }\end{array}$ \\
\hline Composition & $\begin{array}{l}\text { Multiple employment modes, multiple } \\
\text { cohorts, workforce diversity, global } \\
\text { labor markets }\end{array}$ & $\begin{array}{l}\text { Workforce integration, inclusion, } \\
\text { collaborative networks, communities of } \\
\text { practice }\end{array}$ \\
\hline Capability & $\begin{array}{l}\text { Differentiated competencies, multiple } \\
\text { skill bases, human capital resources, } \\
\text { generic/firm-specific }\end{array}$ & $\begin{array}{l}\text { Architectural knowledge, distributed } \\
\text { memory, collective human capital } \\
\text { resources }\end{array}$ \\
\hline Culture(s) & $\begin{array}{l}\text { Professional identities, sub-cultures, } \\
\text { psychological contracts and employment } \\
\text { relationships }\end{array}$ & $\begin{array}{l}\text { Shared enterprise values, beliefs, } \\
\text { assumptions, collective schema }\end{array}$ \\
\hline
\end{tabular}

Our concept of internal alignment in this complex ecosystem is not restricted to simply whether HR practices are mutually reinforcing, but to whether various elements of workforce composition, capabilities, and cultures align and support one another. For example, is the diversity of skill pools (capabilities) matched by the breadth of work modes, and sub-cultures or employment relationships? Or do they conflict with one another? In a related way then, our concept of external alignment addresses whether this HR eco-system is appropriate for the firm's strategy, particularly characterized by its level of complexity. The challenge of the organization is to create an HR ecosystem that incorporates the requisite variety of elements in those subsystems to reflect the complexities of the organization and the 
requirements of the environment, while at the same time identifying how those elements connect and are held together to support one another. The irony is that to increase variety required for external fit and alignment, the organization must absorb variation and difference which places stress on internal alignment. It is in that way that our understanding of complex alignment in the contemporary setting needs to reconcile both these processes of divergence and convergence.

\section{THE QUESTION OF CHANGE}

The twin sister of complexity is change. Just as the original goal of assuring fit and alignment in organizations was to help manage complexity, it can also help firms cope with change. The notion of fit, with its epistemological roots in the field of ecology, connotes achievement of stability or homeostasis where interactive elements balance in equilibrium (Agosta \& Klemens, 2008). It's a beautiful ideal, perhaps, and leads to calming notions of resilience, optimization, best practice, and sustainable competitive advantage. But the reality is that HR systems have an equally important role of accelerating the change process, as well as stabilizing the organization during transition.

When the original frameworks of fit and alignment were proffered, dealing with change was a “sometimes" thing. Our traditional model of industry environments was characterized by what Gould and Eldridge (1977) called punctuated equilibrium - long periods of stability marked by short episodes of change. Stage-based models of organizations were common, where change was seen as "rare, risky, and episodic" (Brown \& Eisenhardt, 1997). The prevailing strategic logic was to devise ways to best cope with change, deal with environmental jolts, and adapt and evolve only as necessary (Meyer, Brooks \& Goes, 1990). Lewin's (1947) model of change was perhaps most popular - unfreeze, change, and refreeze (from state A to state B). Kotter's (1996) eight steps for change were designed to help get things back to normal, consolidate improvements and move on. In many ways, the spirit of that approach persists today in the hearts of many "change fatigue" managers.

But what happens to our concept of strategic alignment if the norm is change, and stability is transitory? In the past couple decades, and seemingly just in the last few years, organizations have been 
undergoing enormous change. Globalization and technological change are disrupting virtually every industry, not just those in the tech sector. Even traditional business models in banking, retail, autos, shipping, even food distribution are being upended. Digital transformation alone is changing the nature of work, the meaning of employment, the shape of culture, and the associated challenges of human resource management (Morris, Shenkar \& Mackey, 2019).

Has our research in SHRM and particularly with regard to alignment kept up the pace? Are our concepts of alignment adequate? Just as with the question of complexity, we can address the issue on at least two levels. How is the concept of change inherent in strategy? And how is change inherent in the workforce? The answer to these questions is reflected in the evolution of HR and how it is conceptualized in terms of a dynamic ecosystem.

\section{Strategic Change—Stable Strategy or Dynamic?}

Rumelt noted that strategy formulation consists of "the constant search for ways in which the firm's unique resources can be redeployed in changing circumstances" (1984: 569). Models of strategy often depict a range of choices with regard to change and adaptation (Chakravarthy, 1982). For example, Miles and Snow's (1978) original typology positioned Defender's at one extreme, establishing a closed system, protecting an existing position, buffering market fluctuations. At the other extreme, Prospectors were purposely open, seeking new opportunities, adapting quickly, and repositioning, even driving change by creating innovations that disrupt the environment for others. In between, Analyzers were Miles and Snow's version of the ambidextrous organization, simultaneously focusing inward to optimize efficiencies while extending outward to create new possibilities.

There are arguments for both extremes. Traditional economic theories are based on assumptions of stable industry structures, and sources of advantage. Caves and Porter's (1977) whole notion of strategy was to erect mobility barriers that solidify advantages across strategic groups. The concept of sustainable competitive advantage is predicated on an equilibrium definition of advantage - one that 
cannot be "competed away through the duplication efforts of other firms" (Barney, 1985: 103). It's pretty easy to conceive of organizational alignment in these contexts.

More challenging, however, is the other extreme, high velocity or hyper-competitive environments of "rapid and dynamic rivalries characterized by unsustainable advantage" (D'Aveni, 1995). When technologies or markets are so new or evolving so quickly that rules of engagement are in constant flux, any competitive advantage tends to be temporary. An open question in these instances is whether firms exhibit changes in strategy, or strategies of change. Do not be too quick to form an answer. If we use the definition of strategy as a "set of goals and resource allocations" or, alternatively, as a "pattern in decisions, activities, and deployments," we need to ask what is stable and what is changing? In addition, how does the relative nature of change affect our notions of alignment?

There are many examples of companies with laudable reputations for strategic alignment and fit who struggled when they did not have sufficient agility to change their strategies, their cultures, and their organizations in the face of disruption (e.g., IBM, Kodak, GE, Microsoft, etc.). Lengnick-Hall and Lengnick-Hall (1988: 460) noted, "Research has shown that achieving fit is not always desirable. Further, a focus on maximizing fit can be counterproductive if organization change is needed." In their description of dynamic capabilities, Teece, Pisano, and Shuen (1997: 520) said that firms need to scan the environment, evaluate markets and competitors, and quickly reconfigure the firm's asset structure, and to accomplish the necessary "internal and external transformation ahead of competition." This sounds as if repeated changes in internal and external fit are inherent in the concept of dynamic capabilities.

Should firms in high velocity environments abandon the notion of fit? Again, the answer is "yes and no." Brown and Eisenhardt (1997) observed that successful innovative firms operate "on the edge of chaos" where the organizational designs are neither so rigid as to control processes nor so random that the processes fall apart. They combine multiple (inconsistent?) aspects of both organic and mechanistic designs (Sine, Mitsuhashi, and Kirsch, 2006). Managers use limited structures - those that focus on clarifying priorities and responsibilities. But they accord more discretion to employees so they can 
improvise and adapt. They communicate extensively to maintain coordination, but don't rely on many rules. Lots of inconsistencies.

In such a setting, "neither planning nor reacting prove effective." Given the pace of change, the future is impossible to predict, so planning proves ineffectual. On the other hand, merely reacting to external change is equally ineffective because it is impossible to react fast enough. Rather, successful managers in these settings tend to conduct low-stakes experiments, probing the environment to explore and test, using rapid feedback cycles to detect what's working, and correct paths forward. As Wieck (1979) noted, alignment in such loosely coupled systems involve fewer rules, but more iterative touch points, effective communication, and mutual adjustment.

Does our research on HR alignment reflect the challenges of change in these organizations? The idea of managing "on the edge of chaos" may be extreme, and certainly not every organization finds itself there. However, for those who recognize its challenges, have our concepts of alignment adequately addressed the underlying dynamics? Traditional notions of internal fit as "consistency and mutually reinforcing sets of practices" are called into question immediately. There's simply too much "chaos" in these organizations to easily apply that definition. What's more, the chaos has functionality - it is the ferment from which innovation evolves. If we define external fit as "alignment with the strategic context," how do we apply that notion when the context is continually disrupted?

We come up a level of abstraction. Instead of conceptualizing alignment with regard to a fixed strategy, say low cost or differentiation, we define it in terms of degree of change, environmental velocity, or dynamic capability. New organizational forms are emerging that give us insight into how firms reframe the challenges of alignment in dynamic environments. Think, for example, of application developers in the software industry, drug researchers in biotech, or technology architects in medical and scientific equipment. Partners in these networks organize with one another to match up their technical capabilities with emerging market opportunities. What often begins as spontaneous sharing of knowledge across partners evolves into a collaborative network that supports many forms of entrepreneurial 
innovation. The advantage of these multi-firm network organizations is that they are more flexible and rapidly adaptive than self-contained firms. But achieving fit and alignment can be more vexing. Why? Several reasons, and they all dictate how we define alignment in this context. For example, the boundaries of the organization are obviously more amorphous and transitory. So what holds these kinds of network organizations together and keeps them aligned? We'd like to say it's due to the HR systems. But is that true? Without formal structure or hierarchy, these communities are knitted together through "selfmanagement" based on shared purpose, values, and "operating protocols" to clarify expectations and guide standards of inter-firm behavior (Miles et al., 2009).

The challenge of alignment in this situation is to combine two countervailing - but complementary - processes of adaptation: convergence and divergence; that is, the system needs to hold the organization together while at the same time forming and reforming its composition. Chakravarthy (1982) described this duality as both, "adaptive specialization" to align with the current environment, as well as "adaptive generalization" to increase the organizational capacity for change and new relationships to the environment. In fact, Collins and Kehoe (2017) found that some types of HR systems promote divergence of ideas and practices within an organization, while other systems focus on convergence. Patel, Messersmith, and Lepak (2013) studied how HR, particularly high performance work systems (HPWS), can help to cultivate contextual ambidexterity, where the organization is both adapting to new opportunities and aligning around clear performance standards and expectations. This is an important study because it helps to show the potential role of HR systems in managing the simultaneity of divergence and convergence. Both processes are important for understanding the HR ecosystem.

Can you have an HR system that supports both convergence and divergence at the same time? The paradox of fit versus flexibility is a familiar one, but one that still has comparatively little research. Wright and Snell (1998: 757) attempted to reconcile the two concepts, suggesting that fit was at "one point in time" whereas flexibility was an enduring trait or capability. In dynamic environments where adaptability is key, (goodness of) fit may not be immediately apparent at a given point in time. Instead, it 
may only become evident over time as - or if - the system increases the organization's probability of long-term survival. We can only measure such fit over time by showing a firm's ability to achieve fit under different conditions.

We have an opportunity to make a bigger impact in this context by rethinking our views of alignment as they relate to SHRM research. If the organizational imperative in dynamic environments is to build capacity for adaptation, then traditional views of fit - which focus on only eliminating variance and achieving convergence - may be an obstacle to change readiness and innovation. Instead, it may be the case that the most appropriate system is one that allows or encourages variation, divergence, even disequilibrium as an initial prerequisite for adaptive capability. Its strategic value would hinge on whether it improved the capacity of the organization to pursue multiple possible futures. This is similar to the principle of real options (Luehrman, 1998), increasing degrees of freedom in an otherwise uncertain world.

At the same time, organizations need a counter-vailing process to reduce non-productive variability by testing and learning, discerning quickly, and rapidly reallocating resources. The two subsystems work together. Worley, Williams, and Lawler (2014) borrowed the ecological notions of "variation, selection, and retention" to describe this phenomenon in agile organizations. Their logic is born of a Darwinian ecology, and it makes good sense. It is also consistent with arguments of Weick (1979) and others that organizations can continue to exist only if they maintain a balance between flexibility and stability - not a compromise position between the two, but a combination of both.

You can see that the challenge is significant. However, the fact is that organizations are tackling the challenge, and succeeding. Our job as researchers is to catch up in how we frame our research. In the end, strategic change requires greater organizational agility, the capacity to assimilate knowledge to drive innovation, and the ability to adapt the organization to benefit from disruption rather than fall victim to it. The HR system helps to orchestrate this dance between divergence and convergence, and our models of alignment need to consider it. 


\section{Workforce Change-Stable Workforce or Dynamic?}

Let's take the logic of change and adaptation further. When it comes to research on HR alignment, an open question is whether the degree of change in the workforce will (should) reflect the degree of change inherent in the firm's strategy and environment. Dynamic capability requires that firms reconfigure their resources - including human resources - and so an important question we need to ask is how the HR system energizes that adaptive process.

Wright and Snell (1999) focused on two broad strategies: (a) resource flexibility and (b) coordination flexibility (cf., Sanchez, 1995). In terms of resource flexibility, the HR challenge is to curate a portfolio of talent with skills that adapt across situations, with the ability to learn quickly, and the capacity to adjust to new situations. In terms of coordination flexibility, organizations can reallocate the mix of human capital, redeploy talent, acquire, release, and reconfigure work arrangements. More crudely, one senior executive told us, "You either need to change the people, or change the people."

In high velocity environments, the need for flexibility in the workforce has been accompanied by more flexible work arrangements. The use of project work, task forces, virtual teams, rotational assignments, and the like all represent more flexible ways of working. In addition to traditional work, we see an increase in alternative employment options that range from fixed-term contracts, temporary agency work, on-call work, 'zero hours contracts', freelance or gig work, and 'crowdsourcing'. In principle, the modularization of work through online platforms can enhance flexibility; although they threaten the stability of existing HR fit models.

What's the upshot of these changes? For one, organizations have more choices, more flexibility in organizing work, which gives them potential for adaptation. But the possibility for workforce fragmentation is real, as is the problem of continuity over time. Companies struggle with control issues as the workforce becomes less tightly connected. Issues of alignment are more important in this context, if only because they are more difficult to ascertain. 
One further effect of a dynamic workforce is that it challenges one particular type of fit: "personorganization" fit (O’Reilly, Chatman, and Caldwell, 1991). How is the nature of psychological attachment shifting? With more options, and more ways to connect, labor markets are more fluid, and increasingly individuals find that their prospects for growth and advancement are better moving across organizations than within them.

How have these dynamics informed our research on HR alignment? Briscoe, Hall, and DeMuth, 2006: 30) noted that, while the concept of boundaryless careers has informed theory for years, "rigorous empirical examinations of these models have lagged behind." And that's a missed opportunity, because as the nature of workforce and employment continue to change, the challenge of alignment is likely to become more important.

Here is one avenue we'd suggest. With looser connections to organizations, where work is less permanent or structured, and boundaries are amorphous, people tend to identify less with a job or a firm itself. People seek out, identify with, and align around a sense of higher purpose, shared values, and ways of interacting. What effect does this have on the culture or climate of the workforce? Could our research on HR alignment take these cognitive and/or affective elements into account, perhaps focusing on more abstract concepts of professional identity, individual purpose, social communities or cultural values? In dynamic environments, these intangibles are among the firm's most important strategic assets. Bowen and Ostroff's (2004) work on HR's role in establishing organizational climate is an important step in that direction. They pointed out that HR systems help create shared perception, interpretation, and common understanding of the organization that reinforces alignment in an otherwise changing environment. We need much more research in this area.

Future research might address how organizations are adapting to create "continuity within change." For example, as the nature of work is more dynamic and adaptive, the importance of a common purpose, values, culture and shared cognition may be more significant. These aspects of alignment are more intangible than our traditional focus on HR practices, but they are no less important in this context. 


\section{An Adaptive Solution-Dynamic Alignment}

What's clear is that a more dynamic workforce (and work environment) invites us to reconceptualize human resources as an ecosystem that incorporates these higher level constructs. Just as with strategy, the HR ecosystem needs to help create a more "dynamic" fit that both reflects the nature of change and helps to support it. Unfortunately, most of our prior research on alignment implicitly casts the organization as a static entity. But it's not. As we've noted some of the most contemporary challenges of strategy and organization involve the process of change. How can we more fully embrace that in our research? Even concepts like dynamic capability tend to be operationalized in our research as stable meta-capabilities of firms, rather than as phenomena in constant flux. So why have we sidestepped this aspect? Perhaps because dynamic qualities are hard to measure. Studying change and adaptation implies studying a phenomenon over time. And our field incentivizes cross-sectional research. That's understandable. And we are guilty.

But the downside is that while we use terminology that suggests dynamic phenomena, our research models are still predicated on the convenience of stability. What can we do? Let's start by flipping a key premise about the relationship between strategy and HR. Most research on alignment takes strategy as given, and HR systems are designed to support it. There's nothing wrong with that, but it limits HR to a role of "strategy implementer." As Lengnick-Hall and Lengnick-Hall (1988) put it, "Rarely are human resources seen as a strategic capacity from which competitive choices should be derived." Our traditional concepts of alignment perpetuate that viewpoint, and may constitute one of the last vestiges of hierarchical planning. Viewed this way, HR is an enabling factor at best and a limiting factor at worst.

What happens when we flip that premise? Is there an argument where HR propels strategy rather than the other way around? Of course there is. As we've seen in research on strategy in high velocity environments, the organization needs to generate new knowledge, new capabilities, innovations and adaptations that emerge from the efforts and exchanges among talented people. Prahalad and Hamel 
(1990) shifted our entire paradigm of strategy when they pointed out that core capabilities - the basis of effective strategy - derive from the collective learning within an organization.

What happens to our conception of HR alignment when we see strategy this way? The central focus of top managers shifts to enhancing new capability development. What does this involve? Investment in a combination of culture, capabilities, and workforce compositions that are configured to create value. Seen this way, the HR ecosystem is not just useful for implementing strategy, it is essential for catalyzing competitive potential.

Companies like Google, 3M, Gore, and others are widely recognized for their use of inside-out (or bottom-up) approaches to innovation and capability development. Their allocation of "free" or personal time to employees gives them the discretion to propose new ideas, seek others in the community with similar prospects, and the capacity to self-organize and explore new ideas and potential innovations. Google News, Gmail, and AdSense were ostensibly germinated from this practice.

The more turbulent the industry environment, where dynamic capability, innovation and agility are foundational to strategy, the more likely it is that the HR ecosystem will play a vital role in developing the capabilities that propel strategic choice. In a nutshell, this is what we mean by a more "adaptive" view of HR alignment. As Colbert (2004) put it, "To be of strategic value, HRM practices should be focused on building and leveraging both creative and adaptive sources of competitive advantage.” We would obviously advocate for more research along these lines.

For example, IBM executives found that when HR managers focus largely on best practice, they lose sight of the constantly shifting demands of a global environment—which require "next" practice. To help focus on next practices, IBM developed a dynamic HR framework that allowed HR managers to constantly renew and reintegrate their practices throughout the organization (Morris and Calamai, 2009).

Our main point is that research on fit and alignment needs to show how the HR ecosystem reflects change, benefits from it, and supports the elements of organizational renewal. The goal of alignment in these instances is not simply to stabilize the organization, but rather to support the adaptive 
process over time. Table 2 depicts the different dynamics that exist within each of the HR sub-systems.

The crux of the problem is that our models are based on assumptions of stability, hierarchical organizations, rationale design, and implementing a plan. Those simply don't work in dynamic environments. The job we have in front of us is to improve our research models and frameworks to more accurately reflect the transformational role of HR, the process of capability development, new ways of working and the enabling of adaptation and renewal.

Proposition 2: in order to address the challenges of alignment in contemporary organizations, we need to frame HR as a more dynamic ecosystem. That system simultaneously creates alignment to the current environment of evolving human capital capabilities, changing cultures, mobile workforce compositions, as well as adaptive potential for strategic change.

Table 2: Alignment Change

\begin{tabular}{|l|l|l|}
\hline Strategy & $\begin{array}{l}\text { Technology disruption, hyper- } \\
\text { competition, innovation, agility }\end{array}$ & $\begin{array}{l}\text { Asset reconfiguration, operating } \\
\text { protocols, mutual adjustment, real } \\
\text { options }\end{array}$ \\
\hline Composition & $\begin{array}{l}\text { Workforce mobility, rapid } \\
\text { deployment, employment flexibility, } \\
\text { temporary work arrangements }\end{array}$ & $\begin{array}{l}\text { Workforce modularity, temporary } \\
\text { collaborations, shared goals }\end{array}$ \\
\hline Capability & $\begin{array}{l}\text { Exploration, experimentation, } \\
\text { shorter half-life of skills, resource } \\
\text { and coordination flexibility }\end{array}$ & $\begin{array}{l}\text { Exploitation, collective sense-making, } \\
\text { negotiated meaning, knowledge } \\
\text { integration }\end{array}$ \\
\hline Culture & $\begin{array}{l}\text { Challenge status quo, cultural } \\
\text { dissolution }\end{array}$ & $\begin{array}{l}\text { Transformation and renewal, hegemony, } \\
\text { shared schema }\end{array}$ \\
\hline
\end{tabular}

What do internal and external fit look like in this context? Our concept of internal fit in this dynamic ecosystem is not restricted to simply whether HR practices are mutually reinforcing, but to whether the dynamics and ongoing changes of workforce composition, capabilities, and cultures support one another. For example, is the process of developing new knowledge (capability) supported by an adaptive culture, or flexible workforce characteristics? When these dynamic sub-systems cohere, they support the internal fit and alignment of the HR ecosystem. In a related way, our concept of external fit in this context is whether this HR eco-system supports - or propels - the firm's strategy, particularly 
characterized by its level of change and adaptation (or holds it back). The challenge of the organization is to create an HR ecosystem that incorporates and enables the emergence of novel elements reflecting the dynamics of strategy, while at the same time identifying how those elements are retained and recombined to enable organizational renewal. But as with the case of complexity, there is an inherent irony in that as the organization creates novelty and new ways of working to improve chances of external fit and alignment for the future, the organization must absorb that variation in the present, placing pressure on the degree of internal fit and alignment. It is in this way that the HR Ecosystem must reconcile both these processes of divergence and convergence over time.

\section{GOING FORWARD}

Let's go back to the analogy of driving in the deep snow. We know that backing up can help us get the traction we need. But do we know why this helps? Well, it has a lot to do with the complex and adaptive driving system of the car and how the wheels engage with the differential. The automotive differential is designed to drive a pair of wheels while allowing them to rotate at different speeds. Sometimes the best way for your wheels to align is for one to spin faster than the other. But that's not all. Because snow conditions are constantly changing, the wheels must be able to sense when one is slipping and put more torque behind the one that is not.

Early models, like Ford's Model T, didn't have a differential. And while they were great innovations that allowed us to get on the road and travel to new places, they couldn't go through deep snow. They obviously wouldn't fit today's travel needs and complex highway infrastructure. The same might be said of our models of HR. Early scholars paved the way by providing models of fit that push for alignment. However, these models do not meet the "differential" needs of organizations today.

\section{Figure 1: HR Ecosystem}




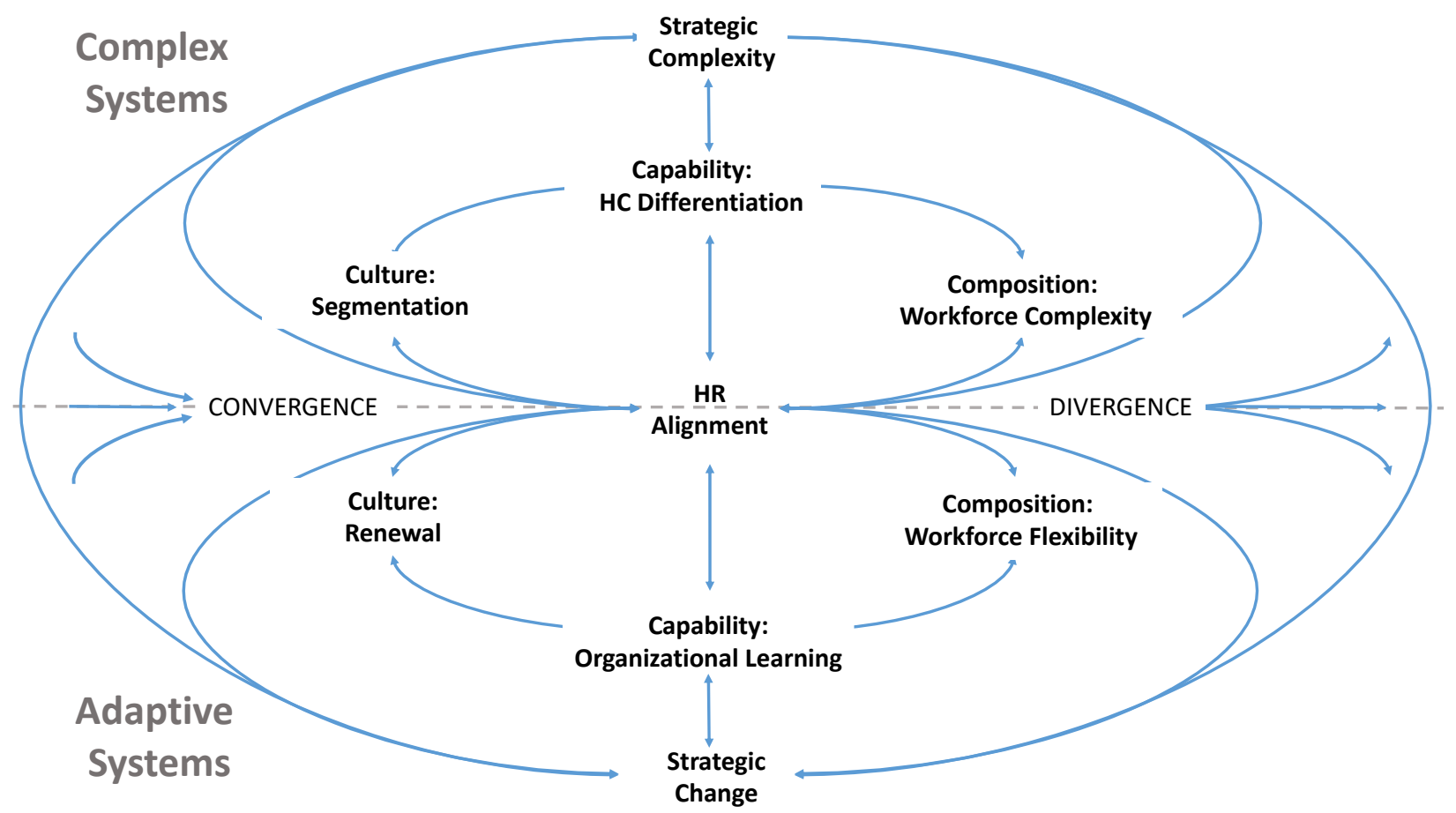

We've proposed several ways that we as a field can more effectively address the challenges of fit and alignment by using the metaphor of an HR ecosystem. The first is to frame alignment as a combination of four sub-systems each with their own complexities: (a) strategy, (b) workforce composition, (c) human capital capabilities, and (d) employment relationships and cultures. This ecosystem has both divergent and convergent properties. Look at the top half of Figure 1 for reference. On the one hand, organizations often increase their level of strategic complexity to match the requirements of a complex environment. Research on alignment would be especially valuable to examine what happens next. We would suggest the following hypotheses.

To support increased strategic complexity, organizations are also likely to increase the level of workforce complexity; that is, employing a more diverse composition of workers in multiple work modes, with varied skills and differentiated human capital, and inevitably, establishing different employment relationships and segmented (sub)cultures. This increased variety - or divergence - is not an obstacle to alignment, or a threat to strategic fit; it may in fact be a requirement for external alignment or fit in a 
more complex ecosystem. But our study of alignment would need to include all (or many) of these subsystems working together. What happens when they do, and what happens when they don't?

Complex systems are intrinsically difficult to model due to the multiplicity of strategies and workforce arrangements that exist within an organization. For example, many of the Fortune 500 companies represent diverse conglomerates with operations in multiple country markets. A senior HR executive at Royal Dutch Shell pointed out to us that part of the difficulty (and advantage) they recognize is the tension of managing multiple strategic objectives, cultural norms, unit-level capabilities, and workforce compositions across the globally distributed organization. Such models are not captured in today's discussions of dynamic capabilities.

But there is another element to managing alignment in this complex HR ecosystem that is also not discussed in the capabilities literature. As the organization increases its level of variation, and the HR ecosystem increases its divergent properties, there is likely to be a concomitant need to increase the integrative - or convergent - properties of the ecosystem as well. Workforce complexity is likely to require (at least some) aspect of unity and commonality, enterprise logic or architectural knowledge that connects differentiated human capital, shared norms, values, and expectations that integrate different subcultures and relationships. Again, these are just hypotheses. But we would argue research that addresses questions such as these are central to understanding fit and alignment in the broader HR ecosystem.

In addition to studying alignment in the context of complexity, we would also encourage further research that captures the dynamics of organizations, their need for agility, transformation, and renewal. Adaptive systems are constantly changing and present a challenge for organizations. Refer to the bottom half of Figure 1 for illustration.

Strategic change is endemic in high velocity environments characterized by disruption, innovation, and shifts due to a growing and constantly shifting market forces. As the organization increases its level of strategic change, how does the HR ecosystem respond? Research on alignment 
would be valuable to better clarify the nature of dynamic fit in the HR ecosystem. Here are a few hypotheses.

To support increased strategic change, organizations are also likely to increase the level of workforce flexibility; that is, establishing more rapid deployment of people, less permanence, and more flexible employment modes. They are likely to increase learning capabilities, creating and sharing new knowledge around the organization, and working to continually reaffirm employment relationships, embracing cultural renewal.

Bob Calamai, an HR executive from IBM, pointed out that part of his challenge was to manage the rapid changes in strategies within the company while also dealing with shifts in the internal culture and workforce composition. He felt that a key to dynamic HR at IBM was to get people to constantly adapt what they were doing while also trying to integrate and solidify the new practices into existing operations.

An ecosystem perspective invites us to study the processes of alignment, not just its static features. It can help to depict the interactions, divergence and convergence among elements of the employment compositions, capabilities and cultures. Because these interactions are myriad and constantly in flux, HR researchers might approach alignment in an evolutionary way by examining where and why practices tend to change and how they are reintegrated into the system to assure consistency and synergy over time. We suspect that sometimes the processes of divergence and convergence occur through managerial intervention (i.e., top-down orchestration), and sometimes they occur more organically (bottom-up adaptation). Part of our responsibility as scholars is to explain how variation occurs and then explain how these changes are assimilated into the organization.

Our traditional research models of alignment do not suffice. If we took a snapshot of the organization at any single moment, certain elements of the HR ecosystem might look out of alignment. But we recognize that they could be serving to evolve the entire ecosystem. A static model would not capture this. The key is not that HR practices are always aligned with the internal and external 
environment. The key is that organizations balance the processes of divergence and convergence to create better alignment over time.

\section{Empirical Application of the HR Ecosystem}

We provide some theoretical and practical advice for understanding, as well as predicting, how we can study this process of divergence and convergence within the HR Ecosystem. To begin, one needs to identify the subsystems involved. We have identified four in this paper that represent ideas or practices that relate to how people are managed by an organization (strategy, composition, capability, culture).

To effectively examine the HR ecosystem, one needs to recognize that subsystems can emerge from the top of the organization, but that they often emerge from a bottom-up process. Hence, studies that only examine top-level managers will miss understanding alignment and how it leads to increased value for the organization. In one of our own research projects with Fortune 500 companies, we found that talking with senior managers provided a very top-down and limited understanding of perceived vs. real processes within the organization. It wasn't until we got down in the weeds and examined individual employees in their different organizational contexts that we were able to see the evolution of processes and how they were often driven from the bottom of the organization (Morris et al., 2009).

Measuring each subsystem requires one to evaluate processes as they occur. For example, measuring the rate of "cultural renewal" in an organization requires that we locate the parties involved in these efforts and either examine their behaviors or ask about their experiences as they relate to the organization. For example, how might globalization of an organization increase divergence of strategies? And how might different HR systems and practices be used to help these strategies converge to one metastrategy for the organization? Answering such questions would help us understand the internal alignment of strategy. Another such example looking at external alignment would then look at how these diverging strategies influence organizational capabilities and build up different cultures and workforce compositions. One might study this process of convergence and divergence as the strategies change, influence the workforce and, in turn, how the workforce influences the strategy. 
Another way of using the HR Ecosystem to improve our understanding of alignment is to examine how different subsystems interact with one another to buffer weaker subsystems and fill in gaps for alignment. For example, if the organizational culture consists of fragmented groups and is not able to coalesce around a common culture, can better aligned capabilities and a more unified workforce compensate for the weakness of the organizational culture. A popular area of study in biological ecology is to examine how, for example, a plant can continue to survive even if one species involved in its pollination dies off or becomes weak. By understanding the interactions of other species involved in the process, scholars can determine how successful a plant is likely to be.

To examine some of these interactions, SHRM scholars might draw upon Bayesian hierarchal methodologies to examine differences across activities and practices (Hansen, Perry \& Reese, 2004). A Bayesian approach could help by examining, the level of strategic change that is occurring in an organization and utilizing additional sources of information from the cultural shifts that have taken place and the capabilities that have been developed to determine how this influences the alignment of practices. Such Bayesian models allow for the inclusion of uncertainty and they allow for predictions of how one or more subsystems might affect another, which classical models do not do (Hansen et al., 2004).

At the end of the day, aspects of capabilities, culture, and composition all influence the strategies organizations select and how such strategies might lead to a more people-focused organization. While we acknowledge that individual studies may not tackle the entire HR ecosystem, we hope that research will begin to more fully portray alignment, as it really is - complex and adaptive.

\section{CONCLUSION}

We set out writing this paper to express what we believe needs to take place within the alignment literature to reinvigorate research on SHRM. We all have a chance (and even a responsibility) to reframe the concept of alignment to better reflect the complexities and dynamics of contemporary strategy. While the theoretical premises of alignment remain useful, few studies have been able to step back and fully convey the realities of organizations and challenges faced by managers. 
Modeling alignment as part of an overarching HR Ecosystem helps highlight the potential patterns among HR deployments and activities influenced by a flexible and multifaceted workforce, its differentiated and evolving human capital capabilities, and evolving cultures. These are all part of a more complex and dynamic approach to strategy. 


\section{REFERENCES}

Abell, D.F. 1993. Managing with dual strategies: Mastering the present, preempting the future. New York: Free Press.

Agosta, S.J. and Klemens, J.A., 2008. Ecological fitting by phenotypically flexible genotypes: implications for species associations, community assembly and evolution. Ecology Letters, 11(11), pp.1123-1134.

Ashby, R.W. 1962. Principles of the self-organizing system. In H. von Foerster and G.W. Zopf (eds.) Principles of Self-Organization. New York: Pergamon, 255-278.

Arthur, J. B. 1994. Effects of human resource systems on manufacturing performance and turnover. Academy of Management Journal, 37(3): 670-87.

Arthur, M.B. and Rousseau, D.M (Eds) 1996. The boundaryless career: A new employment principle for a new organizational era. New York: Oxford University Press.

Barney, J.B. 1986. Types of Competition and the Theory of Strategy: Toward an Integrative Framework, Academy of Management Review, 11(4): 791-800.

Barney, J.B. and Wright, P.M. On becoming a strategic partner: The role of human resources in gaining competitive advantage. Human Resource Management, 37(1): 31-46.

Becker, B.E. and Huselid, M.A., 2006. Strategic human resources management: where do we go from here? Journal of management, 32(6), pp.898-925.

Becker, B. E., Huselid, M. A., \& Beatty, R. W. 2009. The differentiated workforce: Transforming talent into strategic impact. Boston: Harvard Business Press.

Beer, M. Spector, B. Lawrence, P.R., Mills, D.Q and Walton, R.E. 1985. Human resource management, New York: Free Press.

Birkinshaw, J., Bresman, H. and Håkanson, L. 2002. Managing the Post-acquisition Integration Process: How the Human Iintegration and Task Integration Processes Interact to Foster Value Creation. Journal of Management Studies, 37(3): 395-425.

Björkman, I., Stahl, G.K. and Vaara, E., 2007. Cultural differences and capability transfer in cross-border acquisitions: The mediating roles of capability complementarity, absorptive capacity, and social integration. Journal of International Business Studies, 38(4), pp.658-672.

Briscoe, J.P. Hal, D.T. and DeMuth, R.L.F. 2006. Protean and boundaryless careers: An empirical exploration," Journal of Vocational Behavior, 69: 30-47.

Caves, R.E., and Porter, M. 1977. From entry barriers to mobility barriers: Conjectural decisions and contrived deterrence to new competition. Quarterly Journal of Economics, 91: 241-262.

Chadwick, C., 2010. Theoretic insights on the nature of performance synergies in human resource systems: Toward greater precision. Human Resource Management Review, 20(2), pp.85-101.

Camillus, J.C. 1982. Reconciling logical incrementalism and synoptic formalism - an integrated approach to designing strategic planning processes. Strategic Management Journal, 3(): 277-283.

Chakravarthy, B.S. 1982. Adaptation: promising metaphor for strategic management. Academy of Management Review, 7(1): 35-44 
Chesbrough, H. W. 2003. Open Innovation: The new imperative for creating and profiting from technology. Boston: Harvard Business School Press

Chua, C.E.H, Lim, W.K. Soh, C. and Sia, S.K. 2012. Enacting clan control in complex IT projects: A social capital perspective," MIS Quarterly 36(2): 577-600.

Coleman, J.S. 1988. Social capital in the reaction of human capital. American Journal of Sociology. 94: S95-S120.

Collins, C. and Kehoe, R. 2017. Examining strategic fit and misfit in the management of knowledge workers. ILR Review, 70(2): 308-335.

Cross, R., Rebele, R. Grant, A. 2016. Collaborative Overload, HBR, January-February: 74-79).

Cummings, S.; Bridgman, T; Brown, K. 2016. "Unfreezing change as three steps: Rethinking Kurt Lewin's legacy for change management". Human Relations. 69 (1): 33-60.

D'Aveni, R. A. 1995. Coping with hypercompetition: Utilizing the new 7S's framework' Academy of Management Executive, 9(3):

Dierickx, I., and Cool, K. 1989. Asset stock accumulation and sustainability of competitive advantage. Management Science, 35(12): 1504-1511.

Delery, J.E., 1998. Issues of fit in strategic human resource management: Implications for research. Human resource management review, 8(3): 289-309.

Delery, J.E. and Roumpi, D., 2017. Strategic human resource management, human capital and competitive advantage: is the field going in circles? Human Resource Management Journal, 27(1): pp.121.

Eisenhardt, K. M., \& Bourgeois III, L. J. 1988. Politics of decision making in high velocity environments: Towards a midrange theory. Academy of Management Journal, 31(4): 737-770

Floyd, S. W., \& Lane, P. J. 2000. Strategizing throughout the organization: Managing role conflict in strategic renewal. Academy of Management Review, 25: 154-177.

Freeman, R.E. 1984. Strategic Management: a stakeholder approach. Boston: Pitman

Gerhart, B., 2007. Horizontal and vertical fit in human resource systems. Perspectives on organizational fit, 1, pp.317-348.

Gould, Stephen Jay, \& Eldredge, Niles. 1977. Punctuated equilibria: the tempo and mode of evolution reconsidered. Paleobiology 3 (2): 115-151.

Harrison, J.S., and St. John, C.H. 1996. Managing and partnering with external stakeholders. Academy of Management Executive, 10(2): 46-60.

Hill, C.W.L. 1988. Differentiation versus low cost or differentiation and low cost: A contingency framework. Academy of Management Review, 13(3).

Huselid, M.A. 1995. The impact of human resource management practices on turnover, productivity and corporate financial performance. Academy of Management Journal, 38: 635-670.

Jiang, K., Lepak, D.P., Han, K., Hong, Y., Kim, A. and Winkler, A.L., 2012. Clarifying the construct of human resource systems: Relating human resource management to employee performance. Human Resource Management Review, 22(2), pp.73-85. 
Kang, S.C., Morris, S. \& Snell, S.A. 2007. Relational archetypes, organizational learning, and value creation: Extending the human capital architecture. Academy of Management Review, special issue, 32(1): 236-256.

Kehoe, R.R. and Wright, P.M., 2013. The impact of high-performance human resource practices on employees' attitudes and behaviors. Journal of management, 39(2), pp.366-391.

Kehoe, R., Lepak, D.P., \& Bentley, F.S. In Press. Let's call a star a star: Task performance, external status, and exceptional contributors in organizations. Journal of Management

Kotter, J. 1996. Leading change. Harvard Business School Press.

Lawrence, P.R. and Lorsch, J.W. 1967. Differentiation and integration in complex organizations. Administrative Science Quarterly, 12(1): 1-47

Lengnick-Hall, C.A. and Lengnick-Hall, M.L. 1998. Strategic human resources management: A review of the literature and a proposed typology. Academy of Management Review, 13(3): 454-470.

Lewin, Kurt. 1947. "Frontiers in Group Dynamics: Concept, Method and Reality in Social Science; Social Equilibria and Social Change". Human Relations. 1: 5-41.

Luehrman, T. 1998. Strategy as a portfolio of real options. Harvard Business Review, SeptemberOctober, 89-99

MacDuffie, J.P. 1995. Human resource bundles and manufacturing performance: organizational logic and flexible production systems in the world auto industry. Industrial and Labor Relations Review, 48(2): 197-221.

March, J.G. 1991. Exploration and exploitation in organizational learning. Organization Science, 2(1): 71-87.

March, J.G. 1999. The Pursuit of Organizational Intelligence: Decisions and Learning in Organizations. Cambridge:

Blackwell Publishers, Inc.,

Marchington, M., Rubery, J., \& Grimshaw, D. 2011. Alignment integration and consistency in HRM across multi-employer networks. Human Resource Management, 50, 313-339.

Meyer, A.D., Broks, G.R. and Goes, J.B. 1990. Environmental Jolts and Industry Revolutions: Organizational Responses to Discontinuous Change. Strategic Management Journal, 11: 93-110.

Miles, R.E. and Snow, C.C. 1984. Designing strategic human resource systems. Organizational Dynamics, 36: 52.

Mitchell, R.K. Agle, B.R. and Wood, D.J. 1997. Toward a Theory of stakeholder identification and salience: Defining the principle of who and what really counts. Academy of Management Review, 22(4): 853-886.

Moliterno, T. P., \& Mahony, D. M. 2011. Network theory of organization: A multi-level approach. Journal of Management, 37, 443-467.

Morris, S. S., \& Calamai, R. 2009. Dynamic HR: Global applications from IBM. Human Resource Management, 48(4), 641-648. 
Morris, S.M. and Snell, S.A. 2011. Intellectual capital configurations and organizational capability: An empirical examination of human resource subunits in the multinational enterprise, Journal of International Business Studies, 42 (6): 805-827.

Morris, S.M, Snell, S.A. and Bjorkman, I. 2016. Toward an architectural framework for human capital within the global context. Journal of International Business Studies, 57 (6): 723-747.

Nadella, S. 2014. Memo to Microsoft employees, "Satya Nadella announces changes to senior leadership team," posted March 3, 2014.]

Nahapiet, J. and Ghoshal. S. 1998. Social capital, intellectual capital, and the organizational advantage. Academy of Management Review, 23: 242-66.

Ployhart, R.E., Nyberg, A.J., Reilly, G. and Maltarich, M.A. 2013. Human capital is dead; long live human capital resources! Journal of Management, 40(2): 371 - 398.

Olian, J. D. and Rynes, S.L. 1984. Organizational staffing: integrating practice with strategy. Industrial Relations, 23:170-181.

O'Reilly, C.A., Chatman, J. and Caldwell, D.F. 1991. People and Organizational Culture: A Profile Comparison Approach to Assessing Person-Organization Fit. Academy of Management Journal, 34 (3): 487-516.

Osterman, P. 1987. Choice of employment systems in internal labor markets. Industrial Relations, 26(1): 48-63.

Ovide, S. 2015. "Microsoft reaches out to Android, Apple app developers: Microsoft plans to make it easier for developers to modify apps for Windows devices. Wall Street Journal, April 29.

Peteraf, M.A. 1993. The cornerstones of competitive advantage: A resource-based view. Strategic Management Journal, 14: 179-191.

Prigogine, Ilya. 1977. Time, structure and fluctuations. Nobel Lecture, 8 December.

Raisch, S and Birkinshaw, J. 2008. Organizational ambidexterity: Antecedents, outcomes, and moderators, Journal of Management, 34(3).

Rousseau, D.M. and Arthur, M.B. 1999. Boundaryless human resource function: Building agency and community in the new economic era. Organization Dynamics, 27(4): 7-18

Rowe and Wright, P.M. 1997. Related and unrelated diversification and their effect on human resource management controls. Strategic Management Journal, 18 (4) -329- 338.

Rumelt, R. P. 1984. Toward a strategic theory of the firm. In R. Lamb (Ed.), Competitive strategic management: 556-570. Englewood Cliffs, NJ: Prentice-Hall.

Sanchez, R. 1995. Strategic flexibility in product competition. Strategic Management Journal, 16: 135159.

Schuler, R.S. Tarique, I, and Jackson, S.E. 2004, Managing human resources in cross-border alliances, in (ed.) Advances in Mergers and Acquisitions (Advances in Mergers and Acquisitions, Volume 3) Emerald Group Publishing Limited, pp.103 - 129

Snell, S.A. 1992. Control theory in strategic human resource management: The mediating effect of administrative information. Academy of Management Journal, 35: 292-327. 
Schuler, R.S. and Jackson, S.E. 1987. Linking competitive strategies with human resource practices. Academy of Management Executive, 1:207-219.

Shipp, A.J., Furst-Holloway, S. Harris, T.B. and Rosen, B. 2014. Gone today but here tomorrow: Extending the unfolding model of turnover to consider boomerang employees. Personnel Psychology, 67(2): 421-462.

Sine, W.D., Mitsuhashi, H., and Kirsch, D.A. 2006. Revisiting Burns and Stalker: Formal structure and new venture performance in emerging economic sectors. Academy of Management Journal, 49(1) 121132.

Swart, J. and Kinnie, N. 2017. Reconsidering boundaries: Human resource management in a networked world. Human Resource Management, 1-20.

Taleb, N.N. 2012. Antifragile: Things that gain from disorder. New York: Random House.

Takeuchi, R., Lepak, D.P., Wang, H. and Takeuchi, K., 2007. An empirical examination of the mechanisms mediating between high-performance work systems and the performance of Japanese organizations. Journal of Applied Psychology, 92(4), p.1069.

Thomas, D. and Seely Brown, J. 2011. A New Culture of Learning: Cultivating the Imagination for a World of Constant Change. CreateSpace Independent Publishing Platform

Thorelli, Hans. 1986. "Networks: Between Markets and Hierarchies," Strategic Management Journal, 7 (1): 37-51.

Tichy, N.M. Fombrun, C.J. and DeVanna, M.A. 1982. Strategic human resource management. Sloan Management Review, 23: 47-61.

Walker, J.W. 1980. Human resource planning. New York: McGraw-Hill.

Way, S.A., Lepak, D.P. Fay, C.H. and Thacker, J.W. 2010. Contingent workers' impact on standard employee withdrawal behaviors: Does what you use them for matter? Human Resource Management, 49(1): 109-138.

Weick, K.E. 1979. The social psychology of organizing. Wesley, Reading, Mass: Addison Wesley.

Wright, P.M and Snell, S.A. 1999. Toward a unifying framework for Exploring fit and flexibility in strategic human resource management. Academy of Management Review 23(4): 756-772.

Youndt, M.A., Snell, S.A. Dean, J.W., Jr., and Lepak, D.P. 1996. Human resource management, manufacturing strategy, and firm performance. Academy of Management Journal, 39(4): 836-66.

\section{Author Bios:}

Scott Snell (snells@ darden.virginia.edu) is the E. Thayer Bigelow Research Chair in Business Administration and former Senior Associate Dean for Executive Education at the University of Virginia's Darden Graduate School of Business. He teaches courses in strategic management and works with senior executives to help their companies align strategy, organizational capability, and investments in talent.

Shad Morris (morris@byu.edu) received his Ph.D. from Cornell University and is currently the Georgia White Fellow and Associate Professor of Management at the Marriott School of Business, Brigham Young University. He studies how organizations help (and hinder) employees in their efforts to create individual, organizational and societal value. 